\title{
Submarine pipeline lateral instability on a sloping sandy seabed
}

\author{
Fu-Ping Gao ${ }^{\mathrm{a}, *}$, Xi-Ting $\operatorname{Han}^{\mathrm{a}}$, Jing Cao ${ }^{\mathrm{b}}$, Yong Sha ${ }^{\mathrm{b}}$, Jin-Sheng Cui ${ }^{\mathrm{a}}$ \\ a Institute of Mechanics, Chinese Academy of Sciences, Beijing 100190, China \\ ${ }^{\mathrm{b}}$ China National Offshore Oil Company (CNOOC) Research Institute, Beijing 100027, China
}

\section{A R T I C L E I N F O}

\section{Article history:}

Received 10 December 2011

Accepted 12 May 2012

Editor-in-Chief: A.I. Incecik

Available online 2 June 2012

\section{Keywords:}

Sloping seabed

Deepwater pipeline

On-bottom stability

Ocean currents

\begin{abstract}
A B S T R A C T
Ocean-current induced pipeline on-bottom stability on a sloping sandy seabed involves a complex interaction between the hydrodynamic loading, the untrenched pipeline and the neighboring soil. In this study, a newly-designed pipe-soil interaction facility and a flow-structure-soil interaction flume have been utilized for full-scale physical modeling of the pipeline instability on a sloping sand-bed, including the downslope instability and the upslope instability. Unlike the pipeline lateral stability on the horizontal seabed, an initial lateral-soil-resistance is developed and the static-instability might be triggered for the sloping seabed. According to dimensionless analyses, an ultimate lateral-soilresistance coefficient is proposed to describe the interaction of the pipe with the sloping sand-bed. Experimental results indicate that sand-bed slope angle, pipe submerged weight and end-constraints have much influence on pipe on-bottom stability. No matter for the upslope instability or the downslope instability, the corresponding lateral-soil-resistance coefficient for a sloping sand-bed is larger than that for a horizontal sand-bed.
\end{abstract}

(c) 2012 Elsevier Ltd. All rights reserved.

\section{Introduction}

The theme for submarine pipeline on-bottom stability design is the instability criteria under various environmental conditions. To avoid the occurrence of pipeline on-bottom instability, i.e., the pipe breakouts from its as-laid original site, the seabed must provide enough soil resistance to balance the hydrodynamic loads upon the untrenched pipeline. The on-bottom stability of a submarine pipeline involves complex interactions between the wave/current, the untrenched pipeline and the neighboring soil. In the recent decades, numerous experimental studies on the pipeline on-bottom stability have been carried out with $1 g$ mechanical-actuator simulation (e.g., Lyons, 1973; Brennodden et al., 1989; Wagner et al., 1989), with $\mathrm{Ng}$ centrifuge tests for calcareous sand-pipe interaction (e.g., Zhang et al., 2002), and the oscillatory-flow tunnel or wave flume modeling (e.g., Gao et al., 2003, 2007; Teh et al., 2003).

\subsection{Literature review on physical modeling of pipeline on-bottom stability}

\subsubsection{Pipe-soil interaction mechanism}

Before 1970, Coulomb friction theory was employed to estimate the pipe-soil friction force under the action of ocean

\footnotetext{
* Corresponding author. Tel.: +86 10 82544189; fax: +8610 62561284 .

E-mail address: fpgao@imech.ac.cn (F.-P. Gao).
}

waves in shallow waters. However, the pipe-soil interaction experiments by Lyons (1973) showed that, wave-induced pipesoil interaction is too complex to describe with Coulomb friction theory. That is, the pipeline on-bottom stability involves a complex pipe-soil interaction process.

Since the 1980s, base on the results of a series of large scale pipe-soil interaction tests, several pipe-soil interaction models were proposed to predict the ultimate soil resistance to the pipeline in waves. The ultimate soil resistance is defined as the maximum soil resistance to the untrenched pipe against on-bottom instability under the action of environmental loadings including waves, currents, etc. In the pipe-soil interaction model proposed by Wagner et al. (1989), the ultimate soil lateral resistance $\left(F_{R u}\right)$ was assumed as the sum of the two components, i.e., the sliding resistance component and the passive soil resistance component:

$F_{R u}=\mu\left(W_{s}-F_{L}\right)+\beta \gamma^{\prime} A$

where the passive soil force (the second component) modeling the resistance offered by the sand in front of the slightly embedded pipeline is expressed as the effective (buoyant) unit weight of sand $\left(\gamma^{\prime}\right)$ multiplied by a characteristic area $(A)$ and an empirically determined coefficient $(\beta)$. The empirical coefficient $(\beta)$ is a function of the pipe displacement and the lateral loading history (see Wagner et al., 1989). In the energy-based pipe-soil interaction model proposed by Brennodden et al. (1989), the aforementioned soil passive resistance component is, however, relative to the work done by pipe during its movement. In the above two 


\begin{tabular}{|c|c|c|c|}
\hline \multicolumn{2}{|c|}{ Nomenclature } & $g$ & gravitational acceleration; \\
\hline$C_{D}$ & drag force coefficient; & $s$ & lateral displacement of the moving pipe; \\
\hline$C_{I}$ & lift force coefficient; & $U$ & flow velocity of the current; \\
\hline$C_{u}$ & coefficient of uniformity of sand grains $\left(C_{u}=d_{60} / d_{10}\right)$; & $U_{c r}$ & critical flow velocity for the pipe instability; \\
\hline$d_{10}$ & effective size of sand grains; & $W_{S}$ & submerged weight of the pipe per meter; \\
\hline$d_{50}$ & mean size of sand grains; & $\alpha$ & slope angle of the seabed surface; \\
\hline$d_{s}$ & sand grain diameter; & $\phi$ & internal friction angle of soil; \\
\hline$D$ & outer diameter of pipeline; & $\gamma^{\prime}$ & buoyant unit weight of soil $\left(=\gamma^{\prime} \rho_{\text {sat }} g-\rho_{w} g\right)$; \\
\hline$D_{r}$ & relative density of sand; & $\lambda$ & pipe end constraint conditions; \\
\hline$e$ & settlement of pipe while losing stability; & $\mu$ & coefficient of sliding friction; \\
\hline $\begin{array}{l}e_{0} \\
e_{s}\end{array}$ & $\begin{array}{l}\text { initial settlement of the pipe; } \\
\text { void ratio of sands; }\end{array}$ & $\theta$ & $\begin{array}{l}\text { inclination angle of the mechanical loading } \\
\left(\theta=\arctan \left(F_{L} / F_{D}\right)\right) ;\end{array}$ \\
\hline$F_{C u}$ & pipe-soil contact force while pipe instability occurs; & $\rho_{\text {sat }}$ & mass density of saturated sand; \\
\hline$F_{D}$ & drag force on the pipe; & $\rho_{w}$ & mass density of water; \\
\hline $\begin{array}{l}F_{D u} \\
F_{L}\end{array}$ & $\begin{array}{l}\text { ultimate drag force on the pipe; } \\
\text { lift force on the pipe; }\end{array}$ & $\eta_{\alpha}$ & $\begin{array}{l}\text { coefficient of ultimate lateral-soil-resistance for pipe } \\
\text { instability on a sloping seabed; }\end{array}$ \\
\hline$F_{R}$ & $\begin{array}{l}\text { lateral soil resistance to the pipe (parallel to seabed } \\
\text { surface): }\end{array}$ & $\beta$ & $\begin{array}{l}\text { empirical coefficient in the pipe-soil interaction } \\
\text { model by Wagner et al. (1989); }\end{array}$ \\
\hline & $\begin{array}{l}\text { initial lateral soil resistance to the pipe on a sloping } \\
\text { seabed; }\end{array}$ & A & $\begin{array}{l}\text { one half the area of a vertical cross section of the soil } \\
\text { displaced by the pipe during the penetration and }\end{array}$ \\
\hline$F_{R u}$ & ultimate lateral soil resistance for pipe instability; & & \\
\hline
\end{tabular}

pipe-soil interaction models, a few empirical coefficients without implicit physical meanings are difficult to be determined. The underlying physical mechanism for pipe-soil interaction has not yet been well understood, as stated by Hale et al. (1991).

To investigate the interaction of a shallowly-embedded pipeline with the calcareous sand, Zhang et al. (2002) conducted a series of centrifugal tests. A non-associated bounding surface model was then constructed on the basis of test data and the theory of plasticity was used to simulate the response of a pipeline embedded in sandy soil under combined vertical and horizontal monotonic loading.

Foray et al. (2006) studied the pipe-soil interaction with special emphasis on the conditions leading to liquefaction around a pipe. By employing a large-scale experimental setup with an electromechanic actuator to simulate the hydrodynamic loadings, White and Cheuk (2008) investigated the soil resistance on the pipeline during large cycles of lateral movement. To reveal the pipe-soil interaction mechanism for steady-flow induced pipeline on-bottom stability, Gao et al. (2011) conducted a series of tests with an updated pipe-soil interaction facility including a load-displacement synchronous measurement system. It was indicated that, for the equivalent level of dimensionless submerged weight, the value of the critical Froude number for the directly-laid pipe instability in currents is higher than that in waves. Note that the aforementioned studies focused mainly on the pipe-soil interaction modeling with mechanical-actuators for hydrodynamic loading simulations.

\subsubsection{Flow-pipe-soil interaction mechanism}

As aforementioned, the ocean wave/current induced on-bottom stability of a submarine pipeline involves complex flow-pipe-soil interaction, i.e., the interaction between the hydrodynamic loading, the untrenched pipeline and the neighboring soil. Recently, a series of water flume tests have been made to reveal the flow-pipe-soil coupling effects on the wave-induced pipe lateral instability (e.g., Gao et al., 2002, 2003, 2007; Teh et al., 2003).

For simulating the oscillation of water particles near the seabed, a U-shaped oscillatory flow water tunnel was employed to investigate the wave-induced pipeline instability (Gao et al., 2002, 2003). Three characteristic times in the process of pipeline losing lateral stability in waves, i.e., (i) onset of sand scour, (ii) pipe rocking, (iii) pipe breakout, were identified from the pipe displacements records and experimental observations. This process of pipeline instability was also verified with the wave-flume experimental observations by Teh et al. (2003). Based on experimental results, the criteria for the pipeline on-bottom stability on sand-bed for two kinds of constraints, i.e., Case I: the pipe is free at its ends and Case II: the pipe is constrained against rolling, have been established as the following form, respectively (Gao et al., 2003):

$\frac{U_{c r}}{\sqrt{g D}}=a+b \frac{W_{s}}{\gamma^{\prime} D^{2}}$

An improved analysis method was further proposed by Gao et al. (2006) for the on-bottom stability of a submarine pipeline, taking into account the coupling effects between wave, pipeline, and sandy seabed. The proposed improved method comparable with the DNV recommended Practice provides a helpful tool for the engineering practice of pipeline on-bottom stability design.

Local scour at submarine pipelines under the action of currents or waves also drew much attention among numerous researchers, e.g., Sumer et al. (1988), Chiew (1990), Pu et al. (2001), Liang et al. (2005). In those studies, the pipelines were fixed or spring-supported above the soil surface, i.e., the pipeline on-bottom instability was not directly involved. Sand scour, as an indicator of the wave-pipe-soil coupling, was observed usually accompanying in the process of the pipeline losing on-bottom stability (see, Gao et al., 2002). The onset of tunnel scour underneath the shallowly-embedded pipeline (see, Sumer et al., 2001; Zang et al., 2009; Gao \& Luo, 2010) may further induce the occurrence of pipeline spanning.

\subsection{The significant of the pipeline stability on a sloping seabed}

As more and more oil and gas reservoirs having been found at the continental slopes, e.g., in the Western and Northern Gulf of Mexico, the South China Sea etc, the stability of deepwater pipelines on a sloping seabed attracts much attention of engineering designers and researchers. The continental slope is the area between the offshore shallows and where the continental shelf dips steeply to the sea floor. One of most interests to the offshore petroleum industry in Gulf of Mexico is the LouisianaTexas slope, which occupies 120,000 square $\mathrm{km}$ and in which 
a

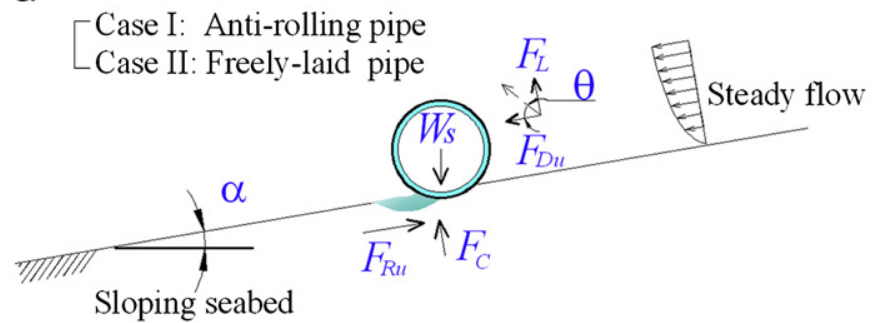

\section{Downslope Instability}

b

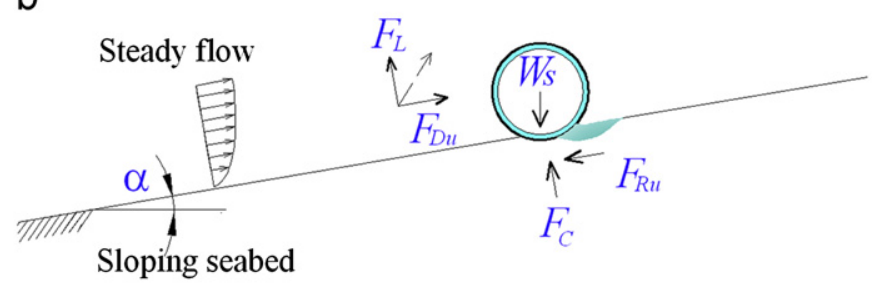

Upslope Instability

Fig. 1. Illustration of the on-bottom instability of a submarine pipeline on a sloping seabed: (a) downslope instability; (b) upslope instability.

bottom slopes range from less than $1^{\circ}$ to greater than $20^{\circ}$ around knolls and basins (Coleman et al., 1989). The seabed in the South China Sea also holds rich varieties of its topographic feature including the vast continental shelf, the continental slope and deep sea basin. At the continental slope of South China Sea, the water depth is generally between 150 and $3500 \mathrm{~m}$, and the seabed slope angles are deep at various locations, e.g., the measured slope angle generally reaches up to $6.7-17.6^{\circ}$ at the western continental slope of South China Sea (Liu et al., 2002).

The influential factor of seabed sloping angle has not been considered in the existing design codes or recommended practices regarding the pipeline on-bottom stability (see, Det Norske, 2007). As the oil and gas exploitation moving into deeper waters, ocean current becomes the prevailing hydrodynamic load upon submarine pipelines (Jones, 1985). However, the aforementioned studies focused mainly on pipeline on-bottom stability on the horizontal seabed. As illustrated in Fig. 1, the lateral on-bottom instability of a submarine pipeline horizontally-laid on a sloping seabed can be mainly categorized into two types, i.e., (i) downslope instability (DI) and (ii) upslope fnstability (UI). The effect of seabed slope angle on the pipeline on-bottom stability is far from being well understood.

In this experimental study, the pipeline on-bottom stability on a sloping sandy seabed is investigated using a newly-designed pipe-soil interaction facility, which is capable of modeling the prototype-size pipeline on an inclined seabed with the slope from 0 to $30^{\circ}$. Meanwhile, a large flow-structure-soil interaction flume is also employed to further simulate the flow-pipe-soil coupling process for pipe losing lateral stability. The effects of seabed slope, pipe submerged weight and end-constraint on the pipeline lateral stability are investigated experimentally.

\section{Pipe instability on a sloping seabed: Full-scale mechanical actuator modeling}

\subsection{Dimensionless analyses}

The ocean-current induced pipeline on-bottom stability on a sloping sandy seabed involves a complex interaction between flow, pipe and its neighboring soil. The ultimate lateral-soilresistance $\left(F_{R u}\right)$ for pipe instability is mainly related to the parameters of the pipeline, sand properties and the characteristics of hydrodynamic loads, i.e.,

$F_{R u}=f\left(\alpha, W_{S}, \mu, \rho_{s a t}, \rho_{w}, g, D, d_{s}, D_{r}, \phi, \tan \theta, e_{0}, \lambda, \ldots\right)$

which can be expressed in the following non-dimensional forms:

$\eta_{\alpha}=f^{\prime}\left(\alpha, G, \mu, \frac{\rho_{\text {sat }}}{\rho_{w}}, \frac{D}{d_{s}}, D_{r}, \phi, \tan \theta, \frac{e_{0}}{D}, \lambda, \ldots\right)$

where the coefficient of ultimate lateral-soil-resistance $\left(\eta_{\alpha}\right)$ is defined as the ratio of the ultimate lateral-soil-resistance $F_{R u}$ $\left(=F_{D u}-W_{S} \sin \alpha\right)$ to the corresponding pipe-soil contact force $F_{C u}$ ( $=W_{S} \cos \alpha-F_{D u} \tan \theta$ ) perpendicular to the surface of the sloping seabed while the pipe losing lateral stability, i.e.,

$\eta_{\alpha}=\frac{F_{R u}}{F_{C u}}=\frac{F_{D u}-W_{S} \sin \alpha}{W_{S} \cos \alpha-F_{D u} \tan \theta}$

in which " $F_{D u} \tan \theta$ " is the lift force exerted on the pipeline in currents; $G$ is the non-dimensional submerged weight of the pipe:

$G=\frac{W_{S}}{\gamma^{\prime} D^{2}}$

The detailed dimensionless analyses on the pipeline on-bottom stability on the horizontal sand-bed $(\alpha=0)$ have been made by Gao et al. (2011).

In this study, the influences of the seabed slope angle $(\alpha)$, pipe end-constraint $(\lambda)$ and submerged weight $(G)$ on the pipe lateral stability are examined intensively. Two types of pipe instability on a sloping seabed have been examined, i.e., (i) upslope instability: the pipe is moving upward along the sloping seabed ( $\alpha$ is positive), and (ii) downslope instability: The pipe is moving downward ( $\alpha$ negative).

\subsection{Experimental setups}

The principal test facility for modeling the pipeline instability on a sloping sand-bed is the mechanical-loaded pipe-soil interaction facility (see Fig. 2(a)). Moreover, a flow-pipe-soil interaction flume (see Fig. 2(b)) was also adopted for the purpose of comparison with the results of pipe-soil interaction tests. The details of the two experimental setups are described as follows.

\subsubsection{Mechanical-loaded pipe-soil interaction simulation}

The pipe-soil interaction facility newly constructed at Institute of mechanics, Chinese Academy of Sciences (IM-CAS), was specially designed for simulating the pipe on-bottom stability on a sloping seabed, which is $5.0 \mathrm{~m}$ long, $1.0 \mathrm{~m}$ wide and $3.2 \mathrm{~m}$ high (the height of sand box is $1.5 \mathrm{~m}$ ), as shown in Fig. 2(a). This facility mainly consists of a test flume with its subsidiary structure, a mechanical-actuator system, and the measurement system, etc. To facilitate the observation of experimental phenomena and data collection, the side-walls of test section are made of toughened glass, and the rests are made of stainless steel plate.

As well-known, the flow-induced hydrodynamic force on the pipe consists of the drag component (parallel to seabed surface and perpendicular to the pipe axis) and the lift component (perpendicular to seabed surface), which can be evaluated with Morison's equation (Morison et al., 1950), i.e.,

$F_{D}=0.5 C_{D} \rho_{w} D U^{2}$

$F_{L}=0.5 C_{L} \rho_{w} D U^{2}$

Based on the results of the variations of $\operatorname{drag}\left(C_{D}\right)$ and lift coefficient $\left(C_{L}\right)$ with the Reynolds number $(R e)$ obtained by Jones 


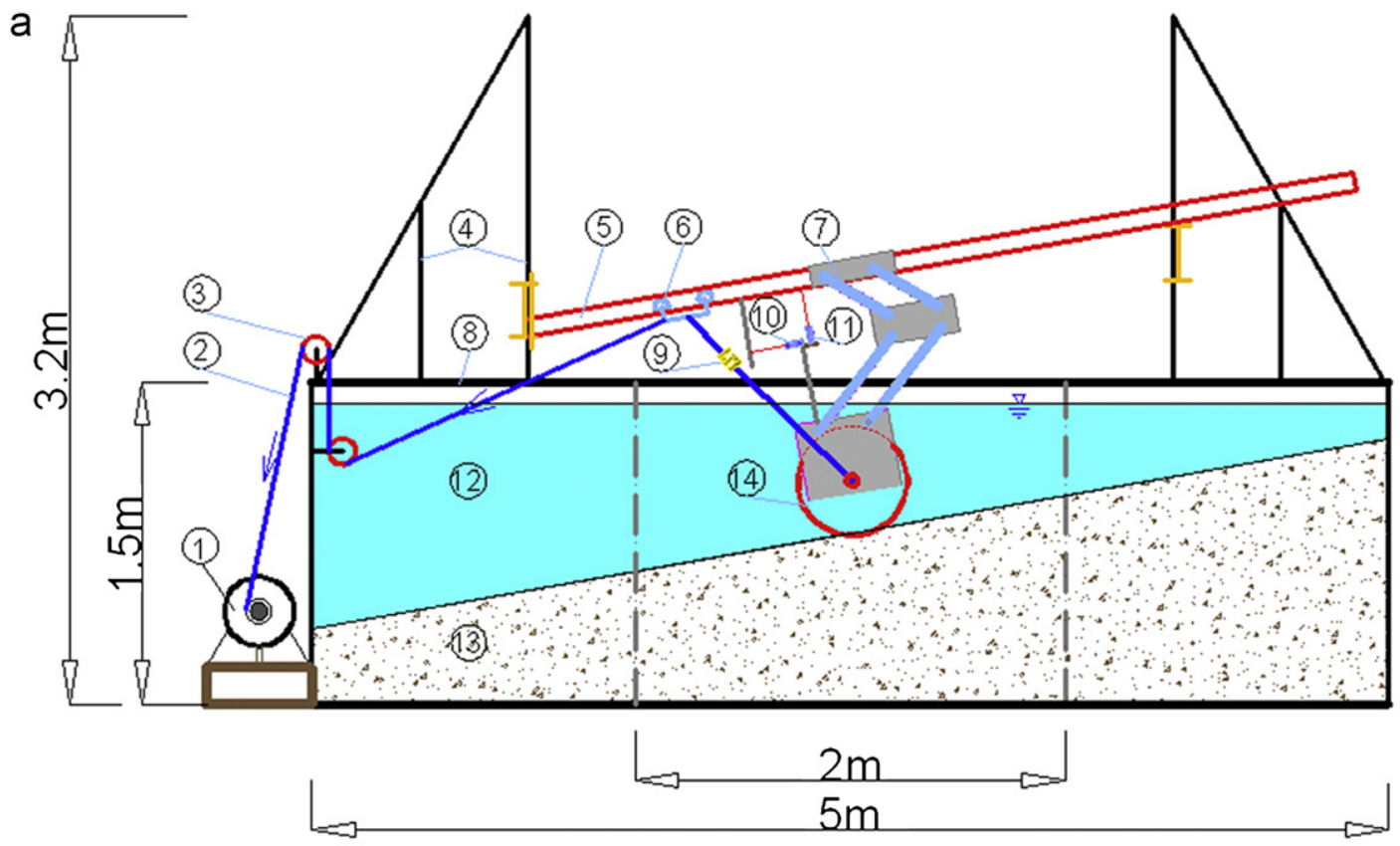

(1) Step motor

(2) Cable

(3) Fixed pulley

(4) Supporting frame

(5) Supporting beam

(6) Live pulley

(7) Anti-rolling device

(8) Test flume

(9) Tension load cell

(10) LDT-1

(11) LDT-2

(12) Water

(13) Sloping sand-bed

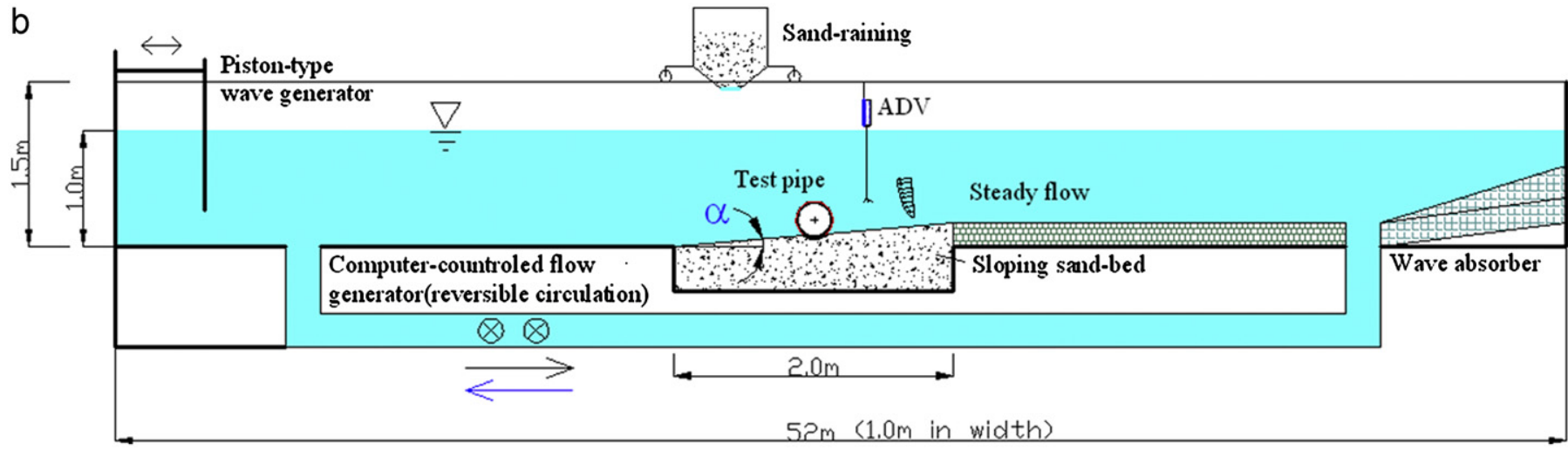

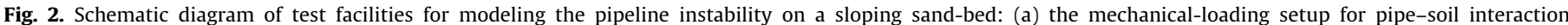
simulation; (b) the water flume at IM-CAS for flow-pipe-soil interaction simulation (not in scale).

(1978), the resultant hydrodynamic load upon the pipe is obliquely upwards with the inclination angle $\theta\left(\approx \arctan \left(C_{L} / C_{D}\right)\right)$ approximately between $53^{\circ}$ and $57^{\circ}$. The detailed analysis regarding the hydrodynamic loads on submarine pipeline in currents was given by Gao et al. (2011).

To simulate the hydrodynamic force on the pipe in the experiments, the mechanical-actuator simulation method has been employed. In the mechanical-actuator system, a displacement-controlled testing program was adopted. A stepper motor was capable of generating an inclined force onto the model pipe via two cables: the front cable with certain length between the pipe and the live pulley, and the other connecting the live pulley and the stepper motor through two fixed pulleys (see Fig. 2(a)). When the position of the supporting beam is given, the angle of the inclined load can be adjusted to a certain value by altering the length of the front cable, on which a tension load cell was installed for measurement of the resultant load from the drag and lift components.

A synchronous measurement system was designed, in which two laser displacement transducers (LDT-1 and LDT-2, see Fig. 2(a)) were employed for the noncontact measurement of pipe displacements, i.e., LDT- 1 for the measurement of the pipe lateral displacement (parallel to the seabed surface); and LDT-2 for the pipe settlement perpendicular to the seabed. Meanwhile, the tension load cell installed along the front cable was used to measure the exerted inclined load onto the model pipe. The experimental phenomena were being recorded concurrently through the transparent glass wall with a digital video camera.

The testing procedure was as follows: (1) the model pipe was laid downward into the water, and the submerged weight was measured with the tension load cell; (2) while the model pipe touching the sand-bed surface, the two laser displacement transducers (LDT-1 and LDT-2) were triggered to measure the pipe movements, including the pipe lateral displacement and its initial settlement into the sloping seabed due to its submerged weight; (3) after the initial settlement finished, the stepper motor was started to impose an inclined-load onto the pipe for simulating steady currentinduced hydrodynamic forces. During the process of the pipe losing lateral stability, the additional settlement and lateral displacement of the test pipe, and the corresponding load onto the pipe were measured simultaneously.

\subsubsection{Flow-pipe-soil interaction simulation in a water flume}

A flow-structure-soil interaction flume (length $\times$ width $\times$ height $=52 \mathrm{~m} \times 1.0 \mathrm{~m} \times 1.5 \mathrm{~m}$ ) at IM-CAS was also employed to further simulate the flow-pipe-soil coupling process for pipe losing lateral stability. This flume is capable of generating reversible steady flow with velocity up to around $0.5 \mathrm{~m} / \mathrm{s}$ at $0.8 \mathrm{~m}$ water depth. A specially designed large soil-box is located in the middle section of the flume, as shown in Fig. 2(b). 
The testing procedure was as follows: (1) The sloping sand bed was prepared with sand-raining technique, which will be described in Section 2.3; (2) The test pipe was then laid onto the sloping sand-bed; (3) subsequently, the steady flow was generated automatically with a computer-controlled system, whose velocity was increasing gradually until the test pipe lost lateral stability. The flow velocity at the level of $1.0 \mathrm{D}$ above the sand-bed was measured with an acoustic Doppler velocimetry (ADV) located in front of the test pipe. Meanwhile, the phenomenon of the pipe losing lateral stability was recorded with a camera through the transparent glass wall. The critical flow velocity $\left(U_{c r}\right)$ for the pipeline on-bottom instability was finally determined according to the experimental observation and the flow velocity measurement.

\subsection{Sand-bed and model pipes}

\subsubsection{Sand-raining technique and the properties of the test sands}

In the aforementioned two test facilities, the saturated sandbeds with certain relative density were prepared by employing the sand-raining technique. Relative density or density index is the ratio of the difference between the void ratios of a cohesionless soil in its loosest state and existing natural state to the difference between its void ratio in the loosest and densest states. While preparing the sloping sand-bed, a sand-carriage with a slotted bottom, through which the dry sand grains inside can fall into the water, was moving to and fro along the side-walls of the flume by altering its speed to obtain a desired slope angle. The rude surface of the sand-bed was then made smooth with a scraper moving along the sand surface.

In the mechanical-loaded pipe-soil interaction modeling, a series of tests have been conducted with the angle of the sandbed surface in the range of $0^{0} \sim 30^{\circ}$, to investigate the influence of slope angle on the pipeline stability. In the flume tests, the medium sand-bed with the slope angle of 0 and $\pm 5^{\circ}$ were adopted for the comparison with the pipe-soil interaction results. Two kinds of sand-bed were adopted to simulate a sandy seabed, i.e., medium sand and silty fine (silica) sand, whose main physical properties are listed in Table 1.

\subsubsection{Test pipes with two kinds of end-constraint}

For a long-distance submarine pipeline, the on-bottom stability for different end constraints is different. The following two end-constraints of the model pipe are taken into account:

(i). End-constraint I: Anti-rolling pipes ( $\lambda=" A ")$. Pipe's rolling is restricted, but the pipe may move freely in parallel and perpendicular direction to the seabed surface. An anti-rolling device has been designed, the lower board of which was fixed to the model pipe. The model pipe was attached through the anti-rolling device upward onto the slantwise supporting beam (see Fig. 1).

(ii). End-constraint II: Freely-laid pipes ( $\left.\lambda={ }^{\prime \prime} F^{\prime \prime}\right)$. The model pipe may rotate around its axis without end constraint, if the lower board of the anti-rolling device is unlocked to the model pipe.

Table 1

Index properties of test sands.

\begin{tabular}{llllllll}
\hline & $d_{50}(\mathrm{~mm})$ & $d_{10}(\mathrm{~mm})$ & $C_{u}$ & $e_{s}$ & $D_{r}$ & $\gamma^{\prime}\left(\mathrm{kN} / \mathrm{m}^{3}\right)$ & $\phi\left(^{\circ}\right)$ \\
\hline Medium sand & 0.38 & 0.30 & 1.46 & 0.791 & 0.32 & 9.03 & 35 \\
Silty-fine sand & 0.11 & 0.07 & 1.57 & 0.793 & 0.16 & 9.02 & 32 \\
\hline
\end{tabular}

Three values of the model pipe diameter at full-scale level are adopted in a series of tests, i.e., $D=0.20,0.35,0.50 \mathrm{~m}$. All of the model pipes are $0.92 \mathrm{~m}$ long, with $40 \mathrm{~mm}$ gaps to the side walls of the test flume. The values of the pipe's submerged weight vary in the range of $0.55<G<1.15$ according to dimensionless analyses (see Eq. (6)), to examine its effects on the pipe on-bottom stability. The coefficient of plexiglass-sand sliding friction $\mu \approx 0.32^{\circ}$.

\section{Experimental results and discussions}

\subsection{Typical features of the pipe losing lateral stability on a sloping sand-bed}

"Static Instability" of the pipeline on a sloping sand-bed: Unlike the case of horizontal seabed $\left(\alpha=0^{\circ}\right)$, for the case of sloping seabed, an initial lateral-soil-resistance $\left(F_{R 0}=-W_{S} \sin \alpha\right)$ is immediately developed while the pipe being laid onto the sloping sand-bed, to balance the component along the seabed surface of the pipe's submerged weight $\left(W_{S} \sin \alpha\right)$, so as to keep the pipe stable even without the action of hydrodynamic loads in currents, as shown in Fig. 3. Otherwise, the directly-laid pipe may lose its lateral stability, even when no external load is exerted. We term this phenomenon as "Static Instability" of the pipeline on a sloping seabed, e.g., the freely-laid pipe loses downslope instability on the sloping sand-bed with $\alpha=-10^{\circ}$, as indicated in Fig. 3(b) (also see, Table 3 in Section 3.3).
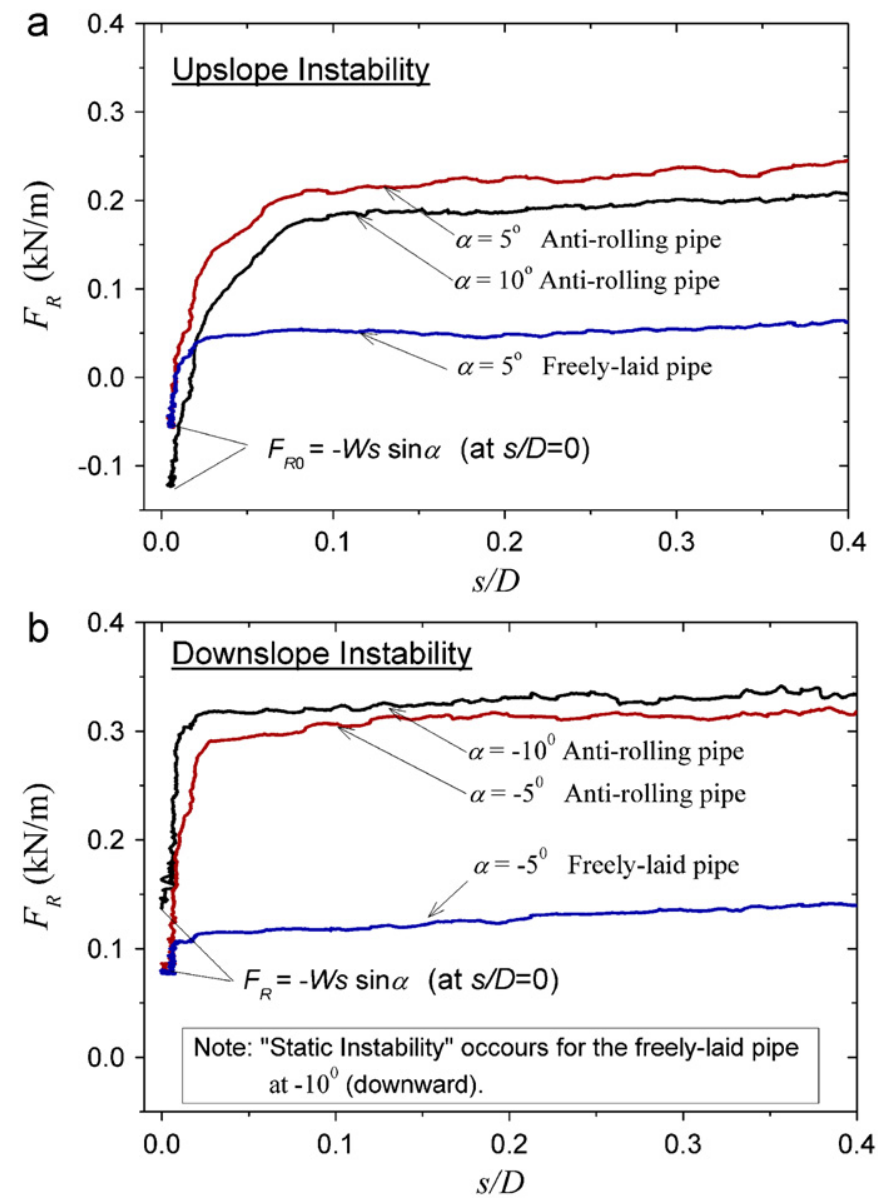

Fig. 3. The development of lateral soil resistance with increasing lateral displacement while the pipe losing stability on a sloping sand-bed: (a) upslope instability; (b) downslope instability. ( $D=0.35 \mathrm{~m}, W_{S}=0.801 \mathrm{kN} / \mathrm{m}, \mu \approx 0.32 \gamma^{\prime}=9.02 \mathrm{kN} / \mathrm{m}^{3}$, $\left.d_{50}=0.11 \mathrm{~mm}, D_{r}=0.16\right)$. 
For the upslope instability (see Fig. 3(a)), with the increase of lateral displacement during the pipe losing lateral stability, the lateral soil resistance (obliquely upward) decreases from certain negative value to zero, and then increases gradually to its maximum value. The ultimate (maximum) soil resistance $\left(F_{R u}\right)$ decreases with the slope angle $(\alpha)$ varying from $5^{\circ}$ to $10^{\circ}$. Meanwhile, the additional settlement of the pipe is being gradually developed with increasing pipe lateral displacement (see Fig. 3).

For the downslope instability (see Fig. 2(b)), the lateral soil resistance increases from certain value $\left(-W_{S} \sin \alpha\right)$ to its maximum/ultimate value $F_{R u}$ with increasing lateral displacement, whose direction is always obliquely upward. The ultimate soil-lateral-resistance $\left(F_{R u}\right)$ increases with the slope angle $(\alpha)$ varying from $-5^{\circ}$ to $-10^{\circ}$. The ultimate soil resistances $\left(F_{R u}\right)$ for downslope instability (see Fig. 3(b)) are bigger than those for upslope instability (see Fig. 3(a)).

The effects of pipe end-constraint on the static stability are quite significant. Experimental observation shows that, static instability occurred to a freely-laid model pipe while being laid on the sloping sand-bed $\left(\alpha=10^{\circ}\right)$. However, the same model pipe with anti-rolling end-constraint kept statically (see Fig. 3). The ultimate lateral-soil-resistance for the anti-rolling pipe is much larger than that for the freely-laid pipe with a fixed value of pipe submerged weight $\left(W_{S}\right)$.

The development of pipe's settlement $(e / D)$ with its lateral displacement $(s / D)$ for a certain slope angles $\left(\alpha= \pm 5^{\circ}\right)$ during pipe losing on-bottom stability is illustrated in Fig. 4. As indicated in this figure, the pipe's settlement varies with its lateral displacement while losing on-bottom stability. The negative sign of ' $e$ ' means the settlement direction is obliquely downward (normal to the sand-bed surface). There exists an initial settlement of the pipe $\left(e_{0} / D\right)$ after being laid onto the seabed surface (see Fig. 4$)$. A similar phenomenon of the variation of pipe's settlement with its lateral displacement has also observed for the case of horizontal sand-bed (see Gao et al., 2011). For both the anti-rolling pipes and the freely-laid pipes, some additional settlement was further developed while the pipe breaking out from its original site. The additional embedment for the anti-rolling pipe is much larger than that for the freely-laid pipe, indicating the pipe's endconstraint affects significantly its embedment into the soil and further affects the ultimate lateral soil resistance. As shown in Fig. 5, while losing on-bottom stability, the pipe is pushing ahead the neighboring sand particles and further inducing the sand upheaval in front of the moving pipe.

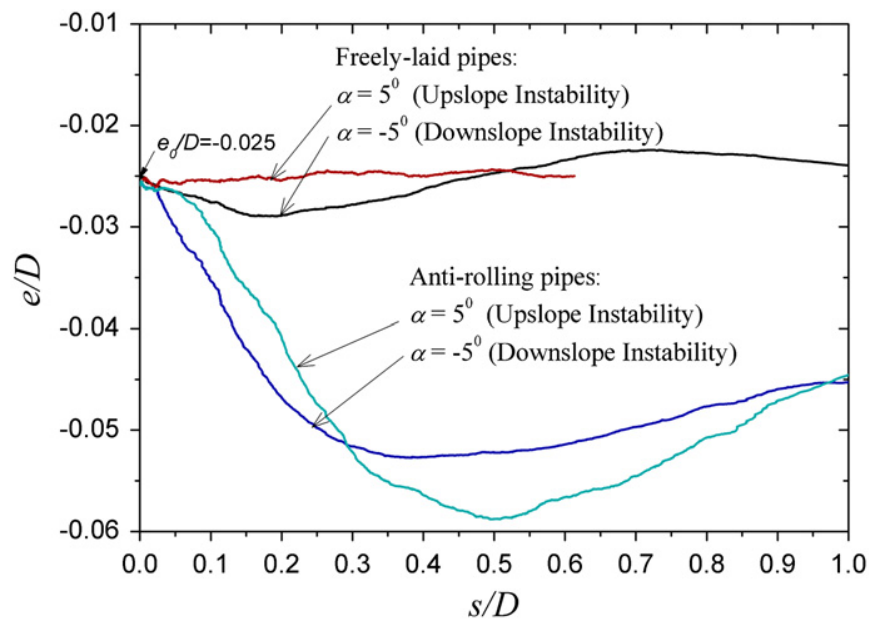

Fig. 4. Additional embedment vs. lateral displacement while pipe losing stability on a sloping sand-bed $\left(D=0.35 \mathrm{~m}, W_{S}=0.801 \mathrm{kN} / \mathrm{m}, \mu \approx 0.32, \gamma^{\prime}=9.02 \mathrm{kN} / \mathrm{m}^{3}\right.$, $d_{50}=0.11 \mathrm{~mm}, D_{r}=0.16$ )

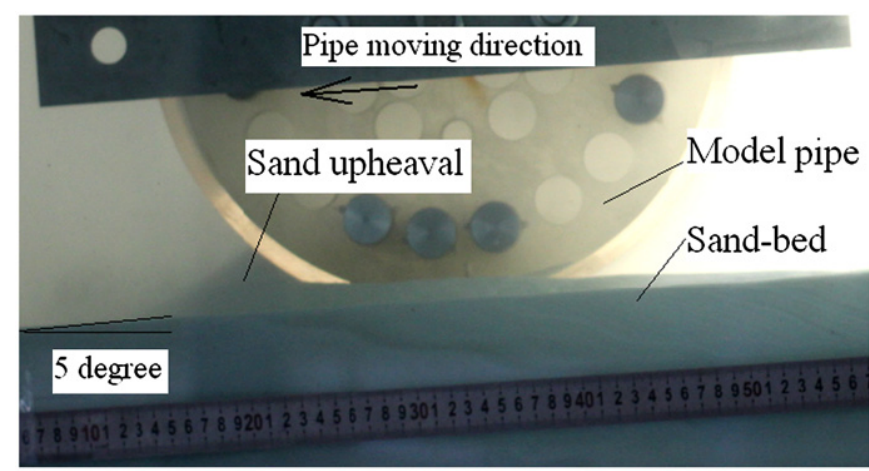

Fig. 5. Experimental observation of the typical configuration of pipe-soil interaction while the anti-rolling pipe losing stability on a sloping sand-bed $\left(\alpha=-5^{\circ}\right.$, $\left.D=0.35 \mathrm{~m}, W_{S}=0.801 \mathrm{kN} / \mathrm{m}, \mu \approx 0.32 \gamma^{\prime}=9.02 \mathrm{kN} / \mathrm{m}^{3}, d_{50}=0.11 \mathrm{~mm}, D_{r}=0.16\right)$.

Table 2

Results of a series of pipe-soil interaction tests for comparison with the flow-pipe-soil interaction tests for the medium sands $\left(d_{50}=0.38 \mathrm{~mm}, D_{r}=0.32\right)$.

\begin{tabular}{lllllllllll}
\hline Test no. & $D(\mathrm{~m})$ & $\alpha\left(^{\circ}\right)$ & $W_{S}(\mathrm{~N} / \mathrm{m})$ & $G$ & $\lambda$ & $F_{D u}(\mathrm{~N} / \mathrm{m})$ & $\eta_{\alpha}$ & $U_{c r}(\mathrm{~m} / \mathrm{s})$ & $F r_{c r}$ \\
\hline M-1 & 0.20 & 0 & 22.6 & 0.063 & $F$ & 2.25 & 0.115 & 0.127 & 0.091 \\
M-2 & 0.20 & 0 & 31.4 & 0.087 & $F$ & 3.68 & 0.139 & 0.162 & 0.116 \\
M-3 & 0.20 & 0 & 49.5 & 0.137 & $F$ & 6.82 & 0.169 & 0.221 & 0.158 \\
M-4 & 0.20 & 0 & 58.5 & 0.162 & $F$ & 8.18 & 0.172 & 0.242 & 0.173 \\
M-5 & 0.20 & 0 & 85.8 & 0.238 & $F$ & 14.05 & 0.209 & 0.317 & 0.226 \\
M-6 & 0.20 & 5 & 22.6 & 0.063 & $F$ & 3.28 & 0.072 & 0.153 & 0.109 \\
M-7 & 0.20 & 5 & 31.4 & 0.087 & $F$ & 6.56 & 0.170 & 0.216 & 0.155 \\
M-8 & 0.20 & 5 & 49.5 & 0.137 & $F$ & 12.47 & 0.250 & 0.298 & 0.213 \\
M-9 & 0.20 & 5 & 58.5 & 0.162 & $F$ & 15.39 & 0.273 & 0.332 & 0.237 \\
M-10 & 0.20 & 5 & 85.8 & 0.238 & $F$ & 26.10 & 0.367 & 0.432 & 0.308 \\
M-11 & 0.20 & -5 & 22.6 & 0.063 & $F$ & 0.63 & 0.120 & 0.067 & 0.048 \\
M-12 & 0.20 & -5 & 31.4 & 0.087 & $F$ & 0.96 & 0.123 & 0.083 & 0.059 \\
M-13 & 0.20 & -5 & 49.5 & 0.137 & $F$ & 1.36 & 0.119 & 0.099 & 0.071 \\
M-14 & 0.20 & -5 & 58.5 & 0.162 & $F$ & 1.41 & 0.115 & 0.101 & 0.072 \\
M-15 & 0.20 & -5 & 85.8 & 0.238 & $F$ & 1.97 & 0.114 & 0.119 & 0.085 \\
\hline
\end{tabular}

\subsection{Comparison with the flume tests}

One of the main advantages for the aforementioned mechanical-loaded pipe-soil interaction testing method is its capability of directly obtaining the ultimate soil resistance to the pipe while losing lateral stability; another one is its modeling pipe instability at full-scale level. The results of the pipe-soil interaction simulation (see Fig. 2(a)) need a validity comparison with the flume tests (see Fig. 2(b)).

In order to make a comparison between the results of mechanical-actuator tests and those of water flume tests, the corresponding equivalent critical flow velocity $U_{c r}$ can be calculated by submitting the ultimate drag force parallel to seabed surface in the mechanical-actuator tests (let $F_{D}=F_{D u}$ ) into Morison's equations (see Eq. (5)), i.e.,

$U_{c r}=\sqrt{\frac{2 F_{D u}}{C_{D} \rho_{w} D}}$

Then, the critical Froude number:

$F_{c r}\left(=\frac{U_{c r}}{\sqrt{g D}}\right)=\sqrt{\frac{2 F_{D u}}{C_{D} \rho_{w} g D^{2}}}$

The results of 15 series of pipe-soil interaction tests are listed in Table 2. Meanwhile, 15 series of water flume tests were also conducted for the comparative study (see Fig. 6). It is indicated in Fig. 6 that, the experimental results for current-induced pipe lateral stability are comparable for various values of sloping angle $\left(\alpha=-5^{\circ}, 0^{\circ}\right.$ and $\left.5^{\circ}\right)$. In the steady-flow flume tests, some local 


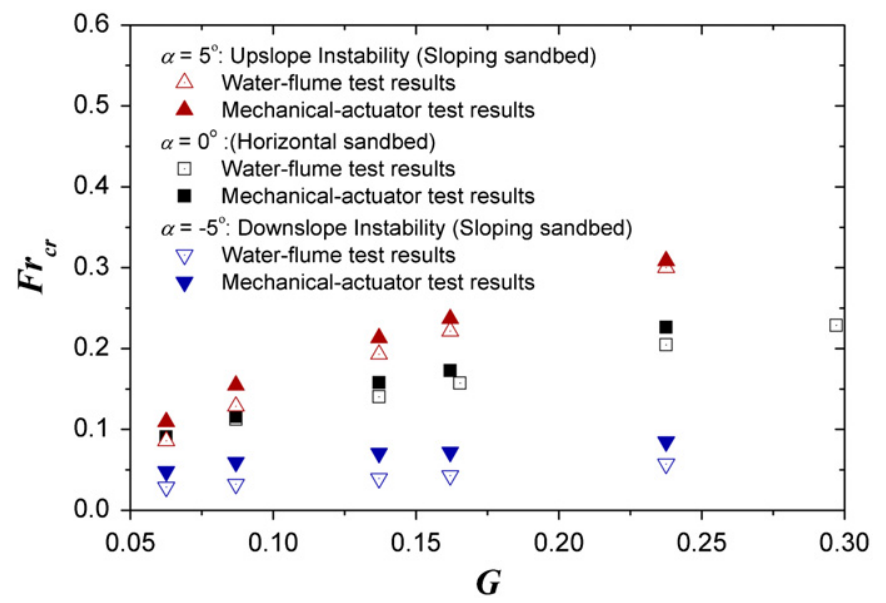

Fig. 6. Comparison between the results of mechanical-actuator tests and those of water fume tests $\left(D=0.20 \mathrm{~m}\right.$; medium sands: $\left.d_{50}=0.38 \mathrm{~mm}, D_{r}=0.32\right)$.

scour around the pipe was observed in the process of the pipe losing lateral stability under the action of currents. For the same value of non-dimensional pipe submerged weight $(G)$, the values of $\mathrm{Fr}_{c r}$ for the present mechanical actuator tests are slightly greater than those for the steady-flow flume tests when increasing the non-dimensional pipe submerged weight. This indicates that the local scour behind the un-trenched pipe reduce the pipeline lateral stability to some extent.

\subsection{Influential factors for pipe lateral instability on a sloping sand-bed}

\subsubsection{Effects of slope angle}

In this study, a series of experiments have been carried out with the newly-designed facility to investigate the effects of slope angle intensively. The results of 41 series of pipe-soil interaction tests for the sloping silty-fine sand-beds are given in Table 3.

Fig. 7(a) gives the variations of the ultimate lateral soil resistance $\left(F_{R u}\right)$ and the corresponding ultimate drag force $\left(F_{D u}\right)$ on the anti-rolling pipes with the slope angle of the sand-bed $(\alpha)$. As indicated in this figure, for a given value of pipe's submerged weight $\left(W_{S}=0.801 \mathrm{kN} / \mathrm{m}\right)$, with the slope angle increases from $-30^{\circ}$ to $30^{\circ}$, the ultimate lateral soil resistance decreases, but the corresponding ultimate drag force increases significantly. Note that, $F_{R u}=F_{D u}-W_{S} \sin \alpha$. As such, the more precipitous the slope is, the bigger the difference between $F_{R u}$ and $F_{D u}$. The ultimate value of soil lateral resistance for downslope instability is larger than that for upslope instability. Due to the influence of the pipe's submerged self-weight, for the case of upslope instability, the drag force firstly balances the component of submerged weight $\left(W_{S} \sin \alpha\right)$ and then balances the lateral soil resistance $\left(F_{R u}\right)$.

Fig. 7(b) shows the variation of the lateral-soil-resistance coefficient $\left(\eta_{\alpha}\right)$ with the slope angle $(\alpha)$.The values of non-dimensional pipe submerged weight $(G)$ for the two pipe diameters $(D=0.35 \mathrm{~m}, 0.5 \mathrm{~m}$, see Fig. 7(b)) are approximately same (Note: $W_{S}=1.523 \mathrm{kN} / \mathrm{m}, G=0.662$, for $D=0.50 \mathrm{~m}$ ). It is indicated that, no matter for the upslope instability (UI) or downslope instability (DI), the lateral-soil-resistance coefficient for a sloping sand-bed is larger than that for a horizontal sandbed. $\eta_{\alpha}$ increases with increasing the value of $|\alpha|$, and the values of $\eta_{\alpha}$ for downslope instability are bigger than those for upslope instability for the same $|\alpha|$ (see Fig. 7(b)). Curve fitting to the experimental data for the variation of $\eta_{\alpha}$ with $\alpha$, the following
Table 3

Results of a series of pipe-soil interaction tests for the sloping silty-fine sand-beds.

\begin{tabular}{|c|c|c|c|c|c|c|c|}
\hline Test no. & $D(\mathrm{~m})$ & $\alpha\left({ }^{\circ}\right)$ & $W_{S}(\mathrm{kN} / \mathrm{m})$ & $G$ & $\lambda$ & $F_{D u}(\mathrm{kN} / \mathrm{m})$ & $\eta_{\alpha}$ \\
\hline S-1 & 0.35 & 0 & 0.801 & 0.725 & $A$ & 0.276 & 0.638 \\
\hline S-2 & 0.35 & 0 & 0.801 & 0.725 & $F$ & 0.096 & 0.143 \\
\hline $\mathrm{S}-3$ & 0.35 & 5 & 0.801 & 0.725 & A & 0.323 & 0.690 \\
\hline S-4 & 0.35 & -5 & 0.801 & 0.725 & $A$ & 0.258 & 0.722 \\
\hline S-5 & 0.35 & 5 & 0.801 & 0.725 & $F$ & 0.140 & 0.114 \\
\hline S-6 & 0.35 & -5 & 0.801 & 0.725 & $F$ & 0.069 & 0.197 \\
\hline S-7 & 0.35 & 10 & 0.801 & 0.725 & $A$ & 0.366 & 0.756 \\
\hline S-8 & 0.35 & -10 & 0.801 & 0.725 & $A$ & 0.225 & 0.745 \\
\hline S-9 & 0.35 & -10 & 0.801 & 0.725 & $F$ & SI & SI \\
\hline S-10 & 0.35 & 20 & 0.801 & 0.725 & $A$ & 0.426 & 0.826 \\
\hline S-11 & 0.35 & -20 & 0.801 & 0.725 & $A$ & 0.174 & 0.861 \\
\hline S-12 & 0.35 & -20 & 0.801 & 0.725 & $F$ & SI & SI \\
\hline S-13 & 0.35 & 30 & 0.801 & 0.725 & $A$ & 0.465 & 0.876 \\
\hline S-14 & 0.35 & -30 & 0.801 & 0.725 & $A$ & 0.115 & 0.956 \\
\hline S-15 & 0.35 & -30 & 0.801 & 0.725 & $F$ & SI & SI \\
\hline S-16 & 0.50 & 0 & 1.523 & 0.675 & $A$ & 0.547 & 0.690 \\
\hline S-17 & 0.50 & 0 & 1.523 & 0.675 & $F$ & 0.159 & 0.121 \\
\hline S-18 & 0.50 & 5 & 1.523 & 0.675 & $A$ & 0.605 & 0.664 \\
\hline S-19 & 0.50 & -5 & 1.523 & 0.675 & $A$ & 0.485 & 0.710 \\
\hline S-20 & 0.50 & 5 & 1.523 & 0.675 & $F$ & 0.252 & 0.101 \\
\hline S-21 & 0.50 & -5 & 1.523 & 0.675 & $F$ & 0.138 & 0.203 \\
\hline S-22 & 0.20 & 10 & 0.221 & 0.613 & $A$ & 0.111 & 1.044 \\
\hline S-23 & 0.20 & -10 & 0.212 & 0.588 & $A$ & 0.078 & 1.096 \\
\hline S-24 & 0.20 & -10 & 0.215 & 0.596 & $F$ & SI & SI \\
\hline S-25 & 0.20 & -10 & 0.212 & 0.588 & $F$ & SI & SI \\
\hline S-26 & 0.20 & 10 & 0.264 & 0.732 & $A$ & 0.134 & 1.079 \\
\hline S-27 & 0.20 & -10 & 0.242 & 0.671 & $A$ & 0.087 & 1.055 \\
\hline S-28 & 0.20 & -10 & 0.253 & 0.701 & $F$ & SI & SI \\
\hline S-29 & 0.20 & -10 & 0.247 & 0.685 & $F$ & SI & SI \\
\hline S-30 & 0.20 & 10 & 0.340 & 0.942 & $A$ & 0.174 & 1.119 \\
\hline S-31 & 0.20 & -10 & 0.320 & 0.887 & $A$ & 0.123 & 1.250 \\
\hline S-32 & 0.20 & 10 & 0.322 & 0.892 & $F$ & 0.089 & 0.167 \\
\hline S-33 & 0.20 & -10 & 0.310 & 0.859 & $F$ & 0.016 & 0.247 \\
\hline S-34 & 0.20 & 10 & 0.397 & 1.100 & $A$ & 0.210 & 1.271 \\
\hline S-35 & 0.20 & -10 & 0.396 & 1.098 & $A$ & 0.159 & 1.280 \\
\hline S-36 & 0.20 & 10 & 0.377 & 1.045 & $F$ & 0.120 & 0.260 \\
\hline S-37 & 0.20 & -10 & 0.385 & 1.067 & $F$ & 0.032 & 0.293 \\
\hline S-38 & 0.20 & 10 & 0.421 & 1.167 & $A$ & 0.222 & 1.256 \\
\hline S-39 & 0.20 & -10 & 0.418 & 1.159 & $A$ & 0.173 & 1.354 \\
\hline S-40 & 0.20 & 10 & 0.420 & 1.164 & $F$ & 0.135 & 0.294 \\
\hline S-41 & 0.20 & -10 & 0.426 & 1.181 & $F$ & 0.059 & 0.392 \\
\hline
\end{tabular}

Note: "SI" represents the occurrence of the "Static Instability" on the sloping sand-bed.

best-fit exponential equation is obtained:

$\eta_{\alpha}=\eta_{0} \exp \left(A_{1} \alpha+A_{2} \alpha^{2}\right)\left\{\begin{array}{l}\langle\text { for UI }\rangle: \eta_{0}=0.624 ; A_{1}=+1.16, A_{2}=-0.978 \\ \langle\text { for DI }\rangle: \eta_{0}=0.624 ; A_{1}=-1.27, A_{2}=-0.886\end{array}\right.$

Note that in Eq. (11), the slope angle " $\alpha$ " is in radian and valid for the examined range of $|\alpha|<\left(\frac{\pi}{6}\right)$. Submitting Eq. (5) into Eq. (11), we can further obtain the ultimate drag force for the lateral instability of anti pipeline on a sloping sand-bed as

$F_{D u}=\left(\frac{\sin \alpha+\eta_{0} \exp \left(A_{1} \alpha+A_{2} \alpha^{2}\right) \cos \alpha}{1+\eta_{0} \exp \left(A_{1} \alpha+A_{2} \alpha^{2}\right) \tan \theta}\right) W_{S}$

\subsubsection{Effects of pipe submerged weight and end-constraint}

The effects of non-dimensional submerged weight of the pipe $(G)$ on the ultimate drag force $\left(F_{D u}\right)$ are shown in Fig. 8(a). For both the anti-rolling pipes and the freely-laid pipes, the ultimate drag force increases with increasing the non-dimensional submerged weight. The values of $F_{D u}$ for upslope instability are larger than those for downslope instability for the same value of $G$ and same pipe end-constraint.

Fig. 8(b) gives the relationship between the lateral-soil-resistance coefficient and the non-dimensional submerged weight for 

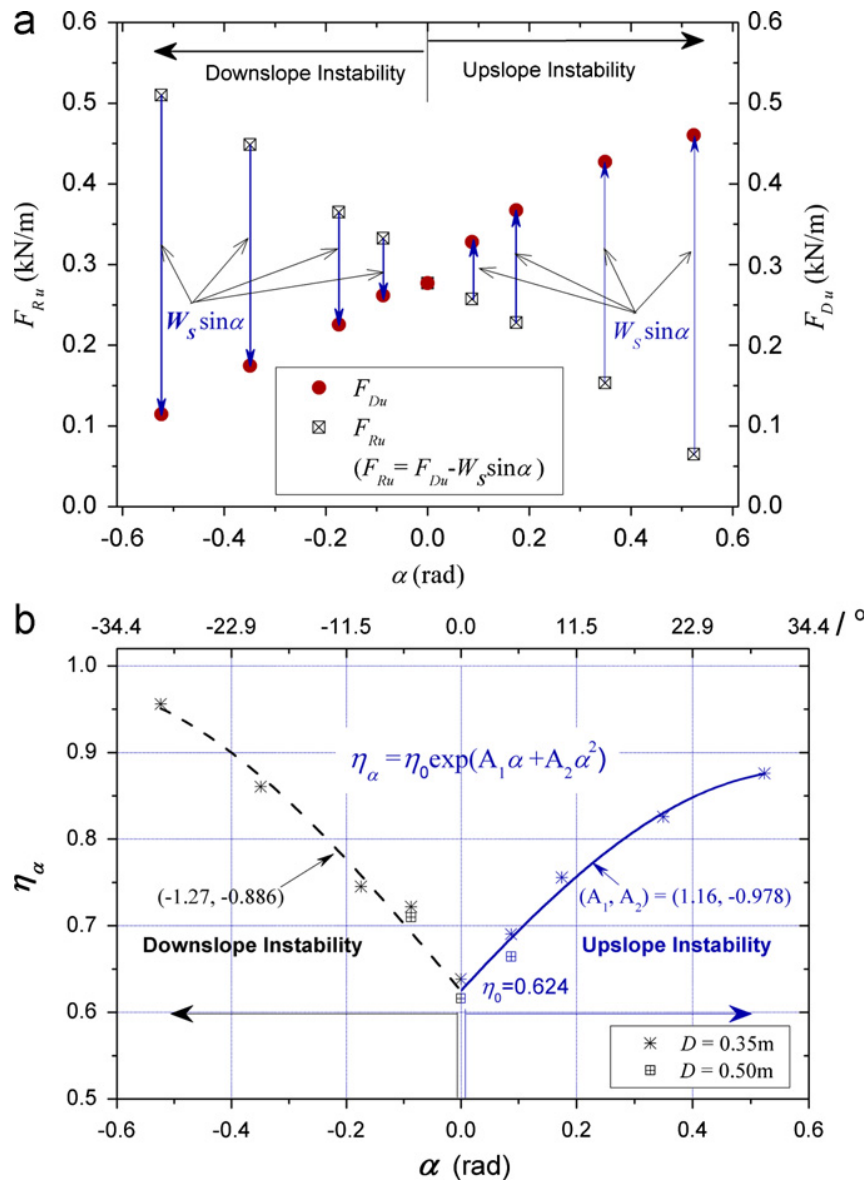

Fig. 7. Effects of slope angle on the on-bottom stability of anti-rolling pipes: (a) ultimate lateral soil resistance vs. slope angle; (b) lateral-soil-resistance coefficient vs. slope angle $\left(D=0.35 \mathrm{~m}, W_{S}=0.801 \mathrm{kN} / \mathrm{m}, G=0.725, \mu=0.32\right.$; Siltyfine sand: $\left.d_{50}=0.11 \mathrm{~mm}, D_{r}=0.16\right)$.

pipe stability on a sloping sand-bed with a certain slope angle $\left(|\alpha|=10^{\circ}\right)$. For all the examined cases, the lateral-soil-resistance coefficient $\left(\eta_{\alpha}\right)$ increases with increasing the non-dimensional submerged weight $(G)$ of the pipes. Static instability occurs to the freely-laid pipes while their submerged weight is less than a certain value (see Fig. 8(b)). The values of the lateral soil resistance coefficient for anti-rolling pipes are much larger than those for the freely-laid pipes. Compared with the instability directions (upslope or downslope), the pipe end-constraints have much more effects on the $\eta_{\alpha}-G$ relationships for pipe stability on a sloping seabed.

\section{Concluding remarks}

The pipeline lateral instability on a sloping seabed is one of the main concerns for the design of submarine pipelines at subsea continental slopes or some special coastal zones. In this experimental study, both a newly-designed pipe-soil interaction facility and a flow-structure-soil interaction flume have been utilized to reveal the mechanism of the steady flow-induced pipe instability on a sloping sandy seabed.

A series of tests have been conducted to full-scale modeling the pipeline lateral instabilities, including the downslope instability and the upslope instability. Unlike the pipeline instability on the horizontal seabed, the "Static Instability" of the pipeline may occur for freely-laid model pipes with certain values of sloping
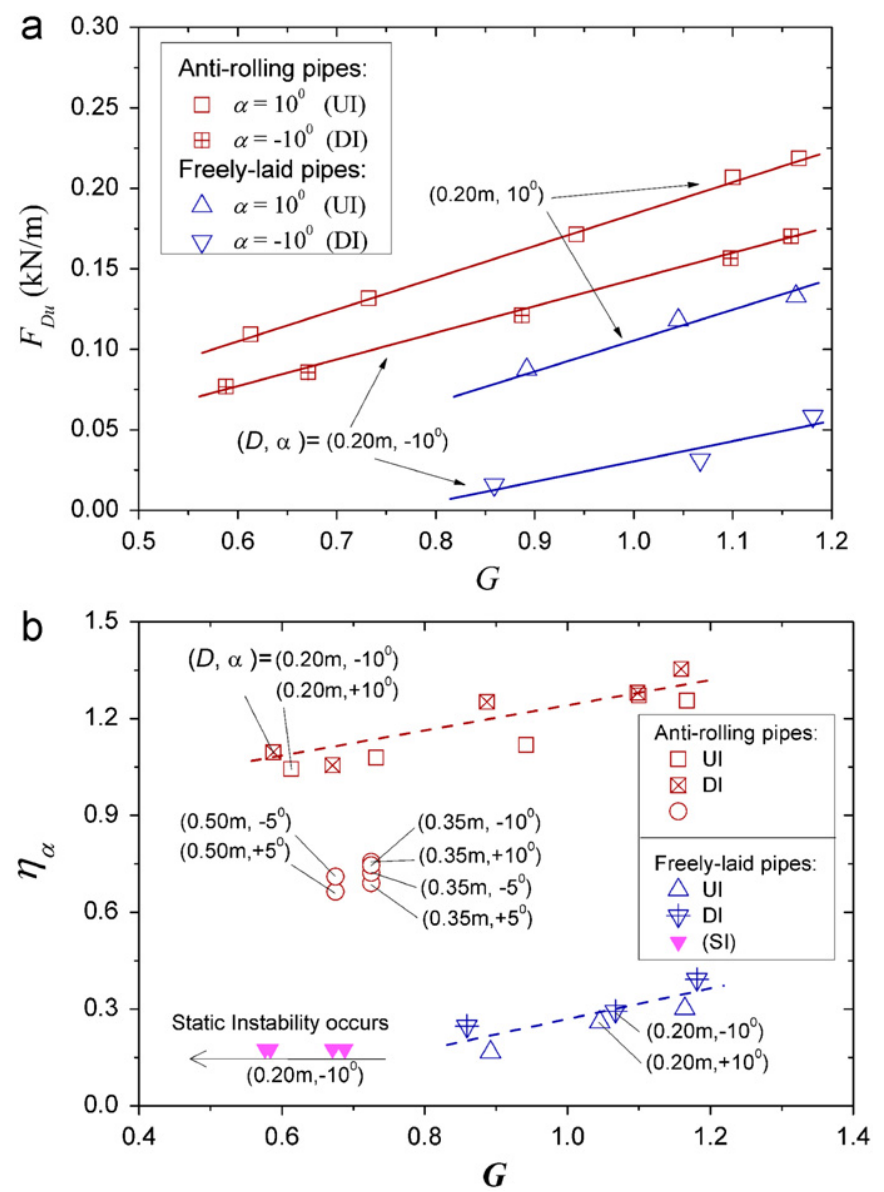

Fig. 8. Effects of non-dimensional submerged weight and end-constraints of the pipeline on the pipe on-bottom stability: (a) ultimate inclined mechanical load vs. non-dimensional submerged weight of the pipe; (b) ultimate lateral-soil-resistance coefficient vs. non-dimensional submerged weight of the pipe $(D=0.20 \mathrm{~m}$, $\mu=0.32$; Fine sands: $d_{50}=0.11 \mathrm{~mm}, D_{r}=0.16$ ).

angle. A validity comparison is made between the pipe-soil interaction simulations and the large flume tests, indicating their results are comparable when the scour effect can be ignorable.

According to dimensionless analyses, an ultimate lateral-soilresistance coefficient $\left(\eta_{\alpha}\right)$ is proposed to describe the pipe-soil interaction on a sloping sand-bed. The on-bottom stability is influenced by the sand-bed slope angle, pipe submerged weight and end-constraints, etc. No matter for the upslope instability or downslope instability, the lateral-soil-resistance coefficient for a sloping sand-bed is larger than that for a horizontal sand-bed. $\eta_{\alpha}$ increases with increasing the value of $|\alpha|$, and the $\eta_{\alpha}$ for Downslope Instability is bigger than that for Upslope Instability. For a given value of the examined slope angles, $\eta_{\alpha}$ increases with increasing the non-dimensional submerged weight $(G)$ of the pipes. The values of lateral soil resistance coefficient for antirolling pipes are much larger than those for the freely-laid pipes.

\section{Acknowledgment}

This work is financially supported by Knowledge Innovation Program of Chinese Academy of Sciences (Grant No. KJCX2-YWL02) and China National S\&T Major Project (Grant No. 2008ZX05026-005-09). Helpful discussion with Senior Engineer $X$. Jia from CNOOC Research Institute and the technical assistances from Mr. F.L. Zhang and Mr. H.T. Zhang are greatly appreciated. 


\section{References}

Brennodden, H., Lieng, J. T., Sotberg, T., Verley R. L. P., 1989. An energy-based pipesoil interaction model. Proceedings of 21st Annual Offshore Technology Conference, OTC 6057, 147-158.

Chiew, Y.M., 1990. Mechanics of local scour around submarine pipelines. J. Hydraul. Eng. ASCE 118 (4), 515-529.

Coleman, J.M., Bouma, A.H., Prior, D.B. and Roberts, H.H., 1989. Nearsurface geology of the Gulf of Mexico continental slope. Proceedings of 21st Annual Offshore Technology Conference, Houston, TX, OTC 5951. 641-648.

Det Norske, Veritas, 2007. On-bottom stability design of submarine pipelines. Recommended Practice DNV-RP-F, 109.

Foray, P., Bonjean, D., Michallet, H., Mory, M., 2006. Fluid-soil-structure interaction in liquefaction around a cyclically moving cylinder. J. Waterw. Port Coastal Ocean Eng. 132 (4), 289-299.

Gao, F.P., Gu, X.Y., Jeng, D.S., 2003. Physical modeling of untrenched submarine pipeline instability. Ocean Eng. 30, 1283-1304.

Gao, F.P., Gu, X.Y., Jeng, D.S., Teo, H.T., 2002. An experimental study for waveinduced instability of pipelines: the breakout of pipelines. Appl. Ocean Res. 24, 83-90.

Gao, F.P., Jeng, D.S., Wu, Y.X., 2006. An improved analysis method for waveinduced pipeline stability on sandy seabed. J. Transp. Eng. ASCE 132 (7), 590-596.

Gao, F.P., Luo, C.C., 2010. Flow-pipe-seepage coupling analysis on spanning initiation of a partially-embedded pipeline. J. Hydrodyn. 22 (4), 478-487.

Gao, F.P., Yan, S.M., Yang, B., Luo, C.C., 2011. Steady flow-induced instability of a partially embedded pipeline: pipe-soil interaction mechanism. Ocean Eng. 38, 934-942.

Gao, F.P., Yan, S.M., Yang, B., Wu, Y.X., 2007. Ocean currents induced pipeline lateral stability on sandy seabed. J. Eng. Mech. ASCE 133 (10), 1086-1092.

Hale, J.R., Lammert, W.F., Allen, D.W., 1991. Pipeline on-bottom stability calculations: comparison of two state-of-the-art methods and pipe-soil model verification. Proceedings of 23rd Annual Offshore Technology Conference Houston, TX, OTC 6761, 567-581.

Jones, W.T., 1978. On-bottom pipeline stability in steady water currents. J. Pet Technol. 30, 475-484.

Jones W.T., 1985. Deepwater pipeline environmental design conditions. Proceeding of Energy Sources Technology Conference \& Exhibition, Dallas, TX, 450-466.

Liang, D.F., Cheng, L., Li, F.J., 2005. Numerical modeling of flow and scour below a pipeline in currents Part II. Scour simulation. Coastal Eng. 52, 43-62.

Liu, Z.S., Zhao, H.T., Fan, S.Q., Chen, S.Q., 2002. Geology of South China Sea. Beijing Science Press, China.

Lyons, C.G., 1973. Soil resistance to lateral sliding of marine pipeline. Proceedings of Fifth Annual Offshore Technology Conference, OTC 1876, 479-484.

Morison, J.R., O'Brien, M.P., Johnson, J.W., Schaaf, S.A., 1950. The forces exerted by surface waves on piles. Pet. Trans. AIME 189, 149-157.

$\mathrm{Pu}, \mathrm{Q} ., \mathrm{Li}, \mathrm{K} ., \mathrm{Gao}$, F.P., 2001. Scour of the seabed under a pipeline in oscillating flow. China Ocean Eng. 15 (1), 129-137.

Sumer, B., Jensen, H.R., Mao, Y., Fredsøe, J., 1988. Effects of lee-wake on scour below pipelines in currents. J. Waterw. Port Coastal Ocean Eng. ASCE 114 599-614.

Sumer, B.M., Whitehouse, R.J.S., Torum, A., 2001. Scour around coastal structures: a summary of recent research. Coastal Eng. 44 (2), 153-190.

Teh, T.C., Palmer, A.C., Damgaard, J.S., 2003. Experimental study of marine pipelines on unstable and liquefied seabed. Coastal Eng. 50, 1-17.

Wagner, D.A., Murff, J.D., Brennodden, H., Sveggen, O., 1989. Pipe-soil interaction model. J. Waterw. Port Coastal Ocean Eng. 115 (2), 205-220.

White, D.J., Cheuk, C.Y., 2008. Modelling the soil resistance on seabed pipelines during large cycles of lateral movement. Mar. struct. 21, 59-79.

Zhang, J., Stewart, D.P., Randolph, M.F., 2002. Modeling of shallowly embedded offshore pipelines in calcareous sand. J. Geotech. Geoenviron. Eng. ASCE 128, 363-371.

Zang, Z.P., Cheng, L., Zhao, M., Liang, D.F., Teng, B., 2009. A numerical model for onset of scour below offshore pipelines. Coastal Eng. 56, 458-466. 